\title{
POLÍTICA SEXUAL NOS ESTADOS UNIDOS: O PESO DAS COMUNIDADES RELIGIOSAS*
}

\author{
Elizabeth Bernstein \\ Janet R. Jakobsen **
}

\section{RESUMO}

Esse artigo versa sobre a análise das alianças entre atores laicos e religiosos nos Estados Unidos, a partir de um estudo de caso sobre a luta contra o tráfico. Ele mostra que o imbricamento entre religião e política tem, nesse caso, duas fontes: o peso das normas e valores veiculados pelas instituições laicas derivadas do protestantismo e a influência das organizações religiosas sobre a política americana - sobretudo a dos evangélicos conservadores, já há mais de quinze anos. A origem das medidas que favorecem as desigualdades de gênero ou de ordem sexual nos Estados Unidos é, portanto, ao mesmo tempo, laica e religiosa. Seria errôneo, todavia, pensar que a religião pende necessariamente para um sentido conservador e a laicidade para um sentido progressista.

Palavras-chave: Estados Unidos. Religião e Política. Laicidade. Igualdade de gênero. Tráfico de seres humanos. Prostituição.

\section{POLITIQUE DU SEXE AUX ÉTATS-UNIS : LE POIDS DES COMMUNAUTÉS RELIGIEUSES}

\section{RÉSUME}

Cet article porte sur l'analyse des alliances entre acteurs laïques et religieux aux États-Unis, à partir d'une étude de cas sur la lutte contre la traite. II montre que l'imbrication entre religion et politique y a deux sources : le poids des normes et valeurs véhiculées par les institutions laïques issues du protestantisme, et l'influence des organisations religieuses sur la politique américaine - celle des évangélistes

* Traduzido da versão francesa para o português por Jaci de Fátima Candiotto e Cesar Candiotto. Revisão da tradução por Naira Pinheiro dos Santos. O texto original em francês, "Politique du sexe aux États-Unis: le poids des communautés religieuses”, Cahiers du Genre, 2012/3 (HS n 3), p. 183-201, foi traduzido do inglês por Jacqueline Heinen.

** Agradecemos a Lucy Trainor, Alison Bilderback, Suzanna Dennison, e Meryl Lodge por sua contribuição a este projeto de pesquisa. 
conservateurs, au premier chef, depuis plus d'un quart de siècle. L'origine des mesures favorisant les inégalités de genre ou d'ordre sexuel aux États-Unis est donc à la fois laïque et religieuse. II serait toutefois erroné de penser que la religion penche nécessairement dans un sens conservateur, et la laïcité dans un sens progressiste.

Mots-clés: États-Unis. Religion et politique. Laïcité. Égalité des sexes. Trafic d'êtres humains. Prostitution.

Há pelo menos trinta anos, os Estados Unidos estão sob a influência de uma coalizão política dominada pelos evangélicos conservadores, à qual o Partido Republicano é mais suscetível, e que fortaleceu a supremacia deste último a nível eleitoral. Deve-se a ela o conservadorismo devastador da política americana em termos de gênero e sexualidade: instrumentalização da ajuda dos Estados Unidos para limitar as liberdades reprodutivas das mulheres no mundo inteiro; promoção da família nuclear sob dominação masculina como ideal de vida privada; e desmantelamento dos dispositivos e programas governamentais que visam a eliminação das discriminações sexuais no plano econômico. Conjugado às exigências neoliberais de privatização dos programas públicos cujos encargos são direcionados a domicílios individuais, esse conservadorismo teve efeitos extremamente negativos para a igualdade entre os sexos, principalmente entre as mulheres pobres e de cor, tanto nos Estados Unidos quanto no resto do mundo. O desembaraçamento da cena política americana da religião potencializaria a igualdade de gênero? É uma ideia tentadora. Como veremos, porém, a seguir, ainda que menos agressivas que o conservadorismo desenfreado da direita religiosa sobre o assunto do gênero e da sexualidade, as correntes laicas desse país, impregnadas de normas cristãs, estão longe de estarem isentas de tradicionalismo e somam frequentemente aí os imperativos neoliberais, através do apoio a medidas contrárias aos interesses das mulheres e que obstaculizam a igualdade de gênero.

A eleição presidencial de 2008 cindiu a coalizão religiosa republicana, abrindo a porta para uma aliança inédita entre o Partido Democrata e os "novos evangélicos" que se acham politicamente moderados. Ainda que possamos esperar que isso desemboque em um tipo de política claramente mais progressista, o resultado está longe da assimilação 
dos temas de gênero e sexualidade. Nesse momento, as representações correm o risco de permanecer imutáveis posto que Barack Obama apoiado ao mesmo tempo pelos/as evangélicos/as progressistas e pelo Partido Democrata - decidiu deslocar o debate público das questões culturais para as questões econômicas. O perigo dessa estratégia se torna evidente em Estados que, como a Califórnia e a Flórida, mantiveram suas posições conservadoras sobre o tema do casamento homossexual, enquanto votavam na liderança política mais progressista de Obama.

Tomadas conjuntamente, as eleições de 2008 trouxeram à tona uma mudança de equilíbrio, tanto no seio de cada um dos grupos cristãos politicamente organizados quanto nas coalizões internas aos partidos, entre militantes cristãos e leigos. Nesses últimos anos, novas alianças foram estabelecidas entre grupos religiosos anteriormente divididos sobre as questões de gênero e de sexualidade: especialmente entre conservadores/as católicos/as e mórmons por ocasião da campanha contra o casamento homossexual na Califórnia, mas também entre conservadores/as protestantes, católicos/as e muçulmanos/as nos meios da política internacional. Ao mesmo tempo, a aliança entre evangélicos/as e Partido Republicano sofreu um deslocamento. A enorme impopularidade do presidente Bush, que encarnava essa coalizão, não somente minou a sua aura política em 2008, como também incitou os grupos evangélicos progressistas a se organizarem politicamente e a apoiar a campanha de Obama e até mesmo o próprio Partido Democrata - o qual, desde então, reivindica mais abertamente a retórica cristã. Entretanto, nenhuma dessas mudanças questionou a influência do cristianismo sobre a política americana. Os partidários de Obama, particularmente, negaram veementemente os rumores sobre a sua pertença ao Islã, sem se perguntar por que seria um problema que um muçulmano fosse candidato à presidência dos Estados Unidos. A eleição de 2008 não modificou em nada, portanto, as representações dominantes concernentes ao gênero e à sexualidade.

\section{RELIGIÃO, SEXO E GÊNERO À LUZ DO CONTEXTO POLÍTICO}

A dificuldade de responder concretamente às desigualdades sexuais e de gênero nos Estados Unidos se deve em parte à imbricação 
histórica da religião na vida política, apesar das declarações oficiais que afirmam o contrário. A primeira emenda à Constituição dos Estados Unidos estabelece claramente a separação entre a Igreja e o Estado, e garante o livre exercício da religião. Na prática, porém, essas injunções permaneceram letra morta. O desacordo opõe aqueles/as para os/as quais o cristianismo representa uma dimensão central no "way of life" americano - aí compreendido no plano legal e político -, e aqueles/as que defendem uma separação mais estrita entre Igreja e Estado (Feldman, 2000).

O segundo problema relacionado à liberdade de culto se deve ao fato que a Corte Suprema dos Estados Unidos definiu os signos públicos do cristianismo como laicos, e não como religiosos. No processo de Lyncj contra Donnelly, em 1984' (Lynch v. Donnelly, 1984, p.465$-668)^{2}$, e novamente naquele de Allegheny County contra ACLU, em 1989 (Allegheny County versus ACLU, 1989, p.492 573), foi decretado que a exposição de símbolos cristãos nos locais públicos no momento da festa de Natal definida como comercial, constituía, antes de mais nada, em um ato laico - no caso de Lynch, o impacto dessa exposição foi julgado “indireto, vago e acessório". As implicações desse raciocínio, apresentadas pela Corte como do puro bom senso, são essenciais para apreender o papel da religião na vida política dos Estados Unidos. Não somente o cristianismo encarna aí a confissão dominante - à qual tribunais e corpos legislativos se referem quase sempre em caso de exigências religiosas - mas, na falta dele, a própria cultura laica pode ser considerada como sendo cristã.

Assim, o problema da hegemonia cristã na cultura americana permaneceria intacto, mesmo que a Constituição americana fosse respeitada. Ainda que despojada de suas roupagens explicitamente religiosas, a legislação profana não deixaria de depender da história cristã e, mais explicitamente, protestante, cujas expectativas impregnam o quadro político inteiro. A influência conjunta do cristianismo sobre a vida política americana, e do protestantismo sobre a laicidade, pesaram fortemente

Lynch v. Donnelly, $465668,1984$.

Allegheny County v. ACLU, 492 573, 1989. 
em matéria de gênero e sexualidade ${ }^{3}$. Cada um dos três poderes do Estado - judiciário, legislativo e executivo - está marcado pelo selo das normas ao mesmo tempo cristãs e laicas derivadas dos protestantes, bem como pela importância da família heterossexual - em particular sob sua forma nuclear.

Diversas vezes, nos Estados Unidos, a hegemonia protestante na vida laica excluiu outros grupos religiosos aprisionando-os nas concepções dominantes - especialmente a prática católica, foi banida do sistema escolar público, o que conduziu ao desenvolvimento de um sistema de educação católico à parte. Sobre os temas do gênero e da sexualidade, a relação entre "laicidade protestante" e catolicismo reconheceu-se muito mais complexa, e ela variou muito no decorrer dos anos. De um lado, os/as evangélicos/as sofreram a influência de católicos/as contrários ao aborto, e personalidades católicas, tais como Phllis Schlafly, participaram na formação da "nova direita” nos anos 1970 (Boyer, 2008); mas, de outro, o Partido Republicano e numerosas organizações protestantes, como a Christian Coalition, não fizeram alianças com as organizações católicas no decorrer dos anos 1990 (Steinfels, 1995). Pelo contrário, sob a administração de George W. Bush, os/as católicos/as se integraram melhor nos círculos republicanos, com um acesso bem melhor aos cargos de responsabilidade, o que não havia sido o caso na época de George W. Bush ou de Ronald Reagan. A esse respeito, convém notar que os temas que são unanimidade entre evangélicos/as e católicos/as conservadores/as e que permitiram a estes/as últimos/as se associarem à administração Bush, versavam precisamente sobre a rejeição do aborto e do casamento gay - daí uma aproximação muito maior por parte dos/as católicos/as americanos/as às das questões sociais do que durante os anos oitenta, quando a guerra, a paz e a

3 A distinção entre a noção de 'laicidade protestante' e a de religião civil vem do fato de que os teóricos da religião se interessam principalmente pela utilização, por parte das instituições laicas, da linguagem e dos símbolos religiosos, tais como a invocação de 'Deus' nos discursos de investidura presidencial. A 'laicidade protestante' nos Estados Unidos, por sua vez, remete às expectativas protestantes que impregnam a linguagem e os conceitos laicos. Por exemplo, o uso reiterado da palavra 'liberdade' no segundo discurso inaugural de George W. Bush não resulta da linguagem que invoca a Deus, mas reflete antes de tudo, as ideias protestantes sobre o tema da liberdade. Para uma análise mais detalhada dessa distinção, ver Jakobsen, Pellegrini 2009. 
justiça econômica estavam no centro de suas preocupações. Em razão do vínculo estreito entre a influência religiosa e as consequências da hegemonia protestante no âmbito laico, a questão do peso da religião no que diz respeito à igualdade dos sexos não pode ser dissociada do contexto laico. Resta saber até que ponto os preconceitos e a retórica que obstaculizam uma semelhante igualdade evoluirão entre os/as cristãos/ãs progressistas que contribuíram para a vitória da campanha presidencial de Obama.

Mesmo na administração Bush, o poder dos/as evangélicos/as dependia da aliança entre conservadores/as cristãos/ãs e leigos/as, constituindo, assim, o solo do Partido Republicano. Os/as evangélicos/ as representam perto de um quarto da população, e somente a metade deles/as - ou seja, doze por cento dos/as habitantes dos Estados Unidos - se declaram "tradicionais" (Green, 2007, apud Goodstein, 2007, p. 41). Sem as redes estabelecidas pelo seu acordo com os/as conservadores/as laicos/as, seria somente uma minoria a mais em um sistema conhecido por sua lentidão em libertar as minorias, salvo no caso de aliança com atores/as mais poderosos/as. Portanto, podemos afirmar que o problema da igualdade dos sexos nos Estados Unidos não reside unicamente na influência da religião, mas na hegemonia do protestantismo no plano, ao mesmo tempo religioso e laico, combinado com a imbricação entre os grupos religiosos socialmente dominantes, a economia neoliberal e os interesses políticos. Portanto, tirar da religião a influência política que ela exerce não resolverá necessariamente os múltiplos problemas ligados à introdução da igualdade em matéria de gênero e de sexualidade porque os preconceitos laicos permanecem, em parte, os mesmos.

\section{UM ESTUDO DE CASO: A LUTA CONTRA O TRÁFICO}

Para sustentar essa afirmação, evocaremos aqui um estudo de caso sobre a gênese e a transformação das políticas de luta contra o tráfico de pessoas, de 2000 até hoje, trazendo à luz o papel desempenhado por militantes evangélicos/as e pelas ONGs, ao lado das feministas laicas, na elaboração das políticas em vigor. Essa pesquisa é baseada em trabalho etnográfico que inclui a análise de documentos políticos, uma metodologia de observação participante, e entrevistas com um uma ampla gama de interlocutores/as: militantes contrários ao tráfico (cren- 
tes e leigos/as) e representantes do governo dos Estados Unidos ${ }^{4}$. Para compreender plenamente a imbricação entre religião e política nesse país, é preciso examinar conjuntamente as políticas internas do Estado e a sua ação no plano internacional, tanto em face de organismos tais como o Banco Mundial, o Fundo Monetário Internacional (FMI) ou as Nações Unidas, quanto através da ajuda financeira e da força militar em escala transnacional. A sociedade civil (movimentos sociais e ONGs que intervêm frequentemente nesses dois níveis) é outro campo de análise importante para apreender essa mesma questão.

O exemplo da luta contra o tráfico mostra que quando dois partidos, mesmo que situados nas duas extremidades do tabuleiro político americano no que concerne aos demais assuntos, partilham as mesmas conjecturas, isso pode dar lugar a alianças eficazes. Dado importante é que os/as defensores/as e os/as políticos/as nem sempre enfatizaram a dimensão especificamente generificada do tráfico humano. No início dos anos 1990, por exemplo, a ação de inúmeras ONGs laicas concentrava-se sobre as diversas formas de atividade ligadas ao tráfico, e não exclusivamente sobre o trabalho sexual das mulheres (Human Rights Watch 1996; Wijers, Lap-hew, 1999). Durante a última década, porém, a notória aliança entre grupos evangélicos e feministas laicas levou a fazer desse último o centro da atenção, conferindo assim mais destaque à questão do tráfico de seres humanos.

Nesses últimos anos, uma série de leis antitráfico (Trafficking Victims Protection Act/TVPA), seja do governo ou dos Estados federais, assimilaram ao tráfico de seres humanos todas as formas de prostituição - interiores ou vinculadas à migração. Tanto uma quanto outra são qua-

4 Para um estudo detalhado dessa pesquisa, ver Bernstein, 2007a e 2010. O relatório disponível no site da UNRISD oferece exemplos de medidas tomadas pelas administrações Bush e Clinton sobre diversos pontos (reforma da proteção social, direitos reprodutivos, casamento homossexual, AIDS), e analisa algumas declarações e posições da administração Obama. Cada u ma tem uma atitude diferente frente às correntes religiosas: Clinton endossou uma versão mais laica da política do Partido Democrata; Bush foi profundamente influenciado pelos evangélicos conservadores do Partido Republicano; e Obama estabeleceu uma aliança com os evangélicos mais progressistas. Ainda que a análise desse último caso implique uma parte de especulação, a administração Obama se diferencia daquelas que a precederam, porque ela sofre mais a influência das correntes religiosas do que a de Clinton, e mais a das correntes progressistas do que na era Bush. 
lificadas de "escravidão moderna", com os principais grupos feministas fazendo referência ao discurso dos direitos humanos, o que significa recolocar a ênfase sobre o preconceito sexual do qual as mulheres são alvo, em detrimento de outras questões, especialmente as econômicas.

Ao mesmo tempo, uma mudança igualmente sensível marcou o movimento dos/as evangélicos/as americanos/as. Se a maior parte dentre eles/as estavam pouco envolvida com a esfera internacional no início dos anos 1990, a reforma de 1996 sobre as normas de participação na ONU facilitou o ingresso de numerosas ONGs filiadas a essa corrente na luta política internacional. Seu crescente interesse pela liberdade religiosa e sua mobilização para defender os/as cristãos/ãs perseguidos/as em todo o planeta levou novos/as atores/as religiosos/as a se envolverem nos debates relativos ao tráfico e a se fazerem ouvir mais sobre o tema dos direitos humanos (Hertzke, 2004; Shapiro, 2004; Castelli, 2007).

Foi assim que uma mudança política iniciada com Clinton encontrou sua plena expressão na época de Bush. Durante os dois anos e meio (de julho de 2004 a dezembro de 2006) em que esteve no comando do Escritório do Departamento de Estado americano de luta contra o tráfico de pessoas, o embaixador John Miller (um judeu ortodoxo que trabalhara anteriormente para o instituto neoconservador Discovery) não cessou de repetir que o uso corrente do termo "trabalhadora do sexo" por parte de diversas ONGs, militantes e universitárias feministas, servia "para justificar a escravidão dos tempos modernos, [e] para conferir dignidade aos criminosos e às indústrias responsáveis por tal servidão" (Miller, 2006). As leis anti-tráfico evocadas acima deram corpo à posição de Miller porque elas introduzem sanções penais progressivas aos cafetões e clientes (considerados, nesse sentido, como verdadeiros escravagistas), impõem sanções financeiras às nações consideradas pouco severas no combate à prostituição (sinônimo, aqui, de tráfico e de escravidão), e estipulam que as ONGs internacionais que não denunciarem explicitamente a prostituição como uma violação dos direitos elementares das mulheres, não poderão se beneficiar de financiamento federal (Saunders 2004; Blumenfeld 2005; United States Congress 2003, 2005). É claro que a lei americana sobre a proteção 
das vítimas do tráfico (TVPA5) inlcui na definição oficial do crime de tráfico humano tanto o trabalho forçado quanto a coerção sexual; e seu alcance é suficientemente amplo para combater violações as mais flagrantes, regularmente cometidas por empresas tais como Verizon, Walmart e Tyson Foods (Chacón, 2006). Mas as prioridades políticas, a atenção da mídia e as ações das ONGs recaem antes sobre a prostituição forçada das mulheres e das meninas, apresentada como o exemplo paradigmático do 'tráfico'.

Outrora, essa questão preocupava somente a polícia local e um número bem restrito de militantes feministas. Mas após os esforços conjuntos de evangélicos/as, de feministas abolicionistas e de representantes do governo bipartido, ela se tornou objeto de uma espiral interminável de programas de militantes laicos/as e religiosos/as, de iniciativas sobre os direitos humanos e de dispositivos jurídicos. Como a influência política das feministas sobre esse tema decorre de sua aliança com os/as cristãos/ãs conservadores/as e neoconservadores/ as, é importante examinar a gama crescente de convicções ideológicas comuns a esses diversos grupos na atualidade. É evidente que a mundialização, a expansão e a diversificação do comércio sexual nas últimas décadas favoreceram a emergência de um consenso entre eles. Prova é que o preâmbulo da lei de 2000 sobre o tráfico (TVPA), peça chave da legislação federal contra o tráfico humano, afirma explicitamente que a explosão da indústria do sexo no decorrer da última década contribuiu amplamente para a adoção da lei. Entretanto, a prioridade política e cultural atribuída à prostituição na luta contra o tráfico humano segue sendo surpreendente em vista das condições de trabalho mais comuns encontradas no trabalho do sexo - ainda que os fatores de coação e coerção sejam aí reforçados pelas desigualdades de raça, de classe, de sexo e de origem étnica. Com efeito, numerosos/as militantes estimam que o quadro jurídico atual do 'tráfico' constitui mais um mal do que um bem para as pessoas afetadas (Doezema, 1998; Saunders, 2004; Agustín, 2007). Tendo em vista a discrepância entre a prostituição forçada e a experiência da maioria daquelas e daqueles - migrantes ou autóctones - que se entregam ao trabalho do sexo, é necessário

N.T.: Sigla para Trafficking Victims Protection Act. 
procurar outras explicações para compreender o teor e a amplitude das campanhas desenvolvidas sobre esse tema nas igrejas, nos campi universitários, nas comunidades militantes e nas assembleias legislativas de diversos Estados.

Um novo círculo de evangélicos/as provenientes de meios instruídos e relativamente favorecidos lideraram campanhas muito incisivas e acaloradas sobre o tema da excravidão sexual e do tráfico de pessoas. Eles não somente mobilizam a linguagem dos direitos das mulheres e da justiça social, como tomam o cuidado de se distanciar das correntes conservadoras. A International Justice Mission (IJM), a mais influente organização cristã contra o tráfico nos Estados Unidos (oficialmente apartidária), que emprega mais de oitenta funcionários/as permanentes em tempo integral e intervém em catorze países, se beneficia do apoio não somente da extrema direita, mas também de renomados/ as evangélicos/as 'de esquerda'. Segundo um empregado da IJM, os/ as assalariados/as da organização - que, para serem contratados/as, devem certificar no plano da fé que são cristãos/ãs e que consagram as primeiras horas de sua jornada de trabalho à oração coletiva - cogitaram até mesmo abandonar o termo ‘evangélico' em função das conotações problemáticas que toma com a ala direita.

Ainda que as campanhas atuais contra o tráfico sejam fortemente sustentadas por cristãos/ãs moderados/as e por liberais, não se poderia dizer que elas encarnam uma linha progressista aos olhos da maior parte dos/as militantes que lutam pelos direitos das trabalhadoras do sexo (ou que defendem um ponto de vista feminista crítico). Diferentemente dos/as evangélicos/as de direita, o programa abolicionista das correntes mais moderadas é mais neoliberal do que tradicionais - atribuindo os problemas sociais antes aos/às indivíduos/as desviantes do que às instituições dominantes, contando mais com a justiça penal do que com o Estado-Providência para remediá-los, incitando antes as ações de benevolência por parte da parcela de privilegiados/as do que a emancipação dos/as oprimidos/as. Tal abordagem evita o ataque às estruturas sociais que levam as mulheres (e muitos homens) mal pagas/os a enveredarem por processos de migração de risco e por empregos informais onde há superexploração, incluindo-se aí as situações relativamente raras, porém 
bem reais, que podem ser justamente qualificadas de 'tráfico' ou de 'escravidão'. Quando examinamos de perto os esforços (financiados pelo governo) dos/as evangélicos/as e das feministas laicas que lutam contra o tráfico, assim como suas tentativas de remediá-lo por meio de soluções claramente comerciais, distinguimos os fundamentos neoliberais (e os limites políticos) das variantes, tanto laicas quanto religiosas, da causa abolicionista dos tempos modernos.

A IJM esteve na vanguarda das campanhas midiáticas recentes de evangélicos/as que deram ares de nobreza ao que poderia ser chamado de "humanitarismo guerreiro". Esse tipo de método é bem conhecido desde o final dos anos 1990, graças aos resgates espetaculares de muIheres e crianças retiradas/os dos bordéis do sudeste asiático (ações frequentemente conduzidas em parceria com órgãos de imprensa tais como "Dateline NBC", "CNN" e "FOX News"). Segundo o esquema 'rescue and restore' ('salvar e restaurar'), patenteado pela organização, seus empregados do sexo masculino se disfarçam de clientes para investigar as casas de prostituição, colaborando com a polícia local para socorrer as/os menores e as/os ocupantes, assim chamadas/os reclusas/ os contra sua própria vontade, e colocá-las/os em centros de reeducação financiados pelo Estado ou por grupos religiosos. Embora essas operações tenham suscitado mais de uma controvérsia (no Camboja, as mulheres escaparam pelas janelas desses centros, amarrando lençóis, a fim de voltarem correndo aos bordéis de Phnom Penh, dos quais elas tinham sido 'libertadas'), o modelo de infiltração proposto pela IJM, muito midiatizado, adquiriu valor de norma entre os/as evangélicos/as e até mesmo para algumas organizações feministas laicas (Soderlund, 2005; Newsblaze, 2007).

Convém notar que numerosos/as evangélicos/as que militam contra o tráfico e defendem a causa abolicionista, não somente apresentam uma visão de mundo análoga à dos/as cristãos/ãs conservadores/as

6 A esse respeito, o comentário de Brian McLaren, eminente pastor evangélico e autor progressista filiado à "Igreja emergente" - e que alguns descreveram como uma "corrente pós-moderna" no seio do movimento evangélico -, constitui uma exceção (Kimball 2003; McLaren 2004, 2008). Por ocasião de uma entrevista com Elizabeth Bernstein, ele declarou que suas três principais prioridades políticas são "o planeta, a pobreza e a paz", defendendo explicitamente maior atenção à dimensão econômica do tráfico de seres humanos. 
sobre a sexualidade, como vão bem mais longe. Nos termos de um permanente convicto do sucesso da operação da IJM, que transformou Svay Pak (localidade do Camboja conhecido por sua prostituição infantil) em "cidade turística agradável”: "nosso verdadeiro objetivo é retirar as pessoas da escravidão para levá-las ao livre mercado". Uma opinião análoga anima as práticas de um número crescente de grupos humanitários cristãos que orientam as antigas prostitutas a empregos de baixo nível na economia dos serviços e lhes ensinam a fazer muffins para a Starbucks ${ }^{7}$ ou a preparar bebidas e pratos de tipo ocidental (Jewell, 2007). Cada vez mais evangélicos/as e feministas laicas aderem a tal concepção: o tráfico de seres humanos deixa de ser coompreendido pelo ângulo da dinâmica global da mundialização, da divisão sexual do trabalho e da migração (quadro de reflexão que sustentava a ação de numerosas ONGs laicas nos anos 1990), para ser entendido como uma questão humanitária para cuja solução os capitalistas mundiais podem contribuir (Baue, 2006; Vital Voices Global Partnership, 2007). Por ocasião da apresentação na Universidade de Columbia de uma mulher bem conhecida, Somali Mom, resgatada do tráfico no Camboja, um representante da Lexis Nexis que a acompanhava discorreu sobre as virtudes das 'parcerias público-privadas' assim como sobre os objetivos de sua empresa: formar as antigas vítimas do tráfico para o exercício de atividades de cabelereira e de costura assim como em empregos manuais menos qualificados. Enquanto os/as altermundialistas da era precedente responsabilizavam o capitalismo pelas condições de trabalho industrial, consideradas inaceitáveis (Ross, 1997; Klein, 2002), os/as novos/as 'internacionalistas' evangélicos/as e seus/as partidários/as laicos/ as consideram esse tipo de procedimento como o próprio exemplo de 'liberdade' (Kristof, 2004a, 2004b).

Assim, a passagem de uma definição ampla do tráfico, que inclui todas as formas de trabalho, a uma definição centrada exclusivamente no trabalho sexual, promove uma visão neoliberal quanto ao modo de abordar o problema e fornecer eventuais soluções. É bem isso que atesta a nova definição legal de tráfico 'doméstico'. Adotada em 2005,

Starbucks é o nome de uma cadeia de cafés americano que vende tortinhas (des pétits gateaux) que, na França, são conhecidas como muffins. (N. do T.) 
a lei sobre a proteção das vítimas (TVPA) é resultado de campanhas dos/as evangélicos/as e das feministas laicas contra o tráfico humano. Ela comporta uma cláusula que caracteriza o crime de 'tráfico doméstico' como um equivalente moral e jurídico do tráfico transnacional, tal como definido anteriormente. 'Tráfico doméstico' e 'tráfico sexual' são utilizados nessa lei como sinônimos; e as outras formas de trabalho que são objeto de tráfico humano, jamais são mencionadas. A fim de reorientar as prioridades dos controles policiais que visam a prostituição de rua nas zonas urbanas, a TVPA prevê a concessão de verbas federais de cinco milhões de dólares a organismos locais encarregados de aplicar a lei para "investigar e perseguir as formas graves de tráfico de pessoas...que estejam sob jurisdição territorial dos Estados Unidos". Essa mudança de definição teve fortes consequências. Inicialmente, para as diversas polícias de costumes que se beneficiaram de fundos de luta contra o tráfico e que puderam revalorizar o estatuto de suas patrulhas semanais encarregadas da prostituição, associando-as ao espectro dos "grupos organizados e complexos de malfeitores" (United States Congress, 2000). Mas também para os membros das redes mais visíveis e mais vigiadas do comércio sexual de rua. Como especificado por ocasião de uma conferência no Departamento Americano de Saúde e de Serviços Humanos sobre resgatados/as do tráfico sexual, em outubro de 2006, os proxenetas podem agora ser acusados do crime federal de tráfico e condenados a penas de prisão de até noventa e nove anos; as prostitutas podem ser detidas legalmente para garantir seu testemunho na acusação contra os 'traficantes'; e os clientes (cuja demanda por serviços de prostituição é definida pela TVPA como a causa subjacente do tráfico) podem ser detidos e seus veículos apreendidos em prol do financiamento das atividades 'antitráfico'. Essas novas disposições adquiriram força de lei em escala federal graças à colaboração estreita de militantes evangélicos/as e feministas contra o tráfico com os grupos de reflexão neoconservadores de Washington. Elas refletem uma convergência entre o 'humanitarismo guerreiro' dos/as evangélicos/as e o que podemos qualificar de 'feminismo carcerário', a saber, a adesão das feministas abolicionistas a um programa de ordem pública. Como mostrou a politóloga Marie Gottschalk a respeito dos movimen- 
tos norte-americanos contra as mulheres espancadas e violadas, essa postura envolve geralmente um desvio, no sentido de que as feministas recorrem antes ao aparelho carcerário do que ao Estado-providência para alcançar seus objetivos (Gottschalk, 2006).

Desde então, as raízes da 'escravidão dos tempos modernos' não residem mais nos fatores estruturais e nas instituições dominantes, mas nos indivíduos desviantes: estrangeiros de pele escura ou afroamericanos que vivem no centro da cidade. O que mais surpreende, porém, na linha do movimento abolicionista atual sobre os costumes sexuais é que ela resulta não somente da adesão conjunta de feministas e de liberais laicos/as ao neoconservadorismo e à política carcerária, mas também do giro à esquerda de alguns/mas evangélicos/as, que passaram de posições conservadoras sobre o aborto e o casamento gay a uma teologia que conjuga 'novo internacionalismo' e justiça social.

Sob mais de um aspecto, a aliança entre conservadores/as cristãos/ãs e feministas laicas abala os preconceitos habituais quanto ao peso da religião em matéria de igualdade entre os sexos. À medida que alguns grupos cristãos do movimento antitráfico defenderam, ademais, políticas percebidas geralmente como contrárias a essa igualdade, sua aliança com feministas políticas de renome mostra que os critérios de definição relativos à assim chamada 'igualdade entre os sexos' estão longe de ser homogêneos. O exame dos pontos comuns que fundamentam a aliança dessas duas correntes nos Estados Unidos nos leva igualmente a perguntarmo-nos se o modelo de justiça sexual e de gênero promovido pelo movimento antitráfico permite mensurar a referida igualdade segundo os grupos de idade, de classe, de origem étnica ou religiosa das mulheres afetadas. E também a nos indagarmos sobre o meio mais seguro de instaurá-lo: confiar no sistema de justiça penal ou nas intervenções da polícia e do exército constitui a melhor maneira de delimitar as múltiplas causas sociais do 'tráfico', enquanto problema sexuado?

No plano político e cultural, a mobilização dos/as evangélicos/as confere mais visibilidade a toda uma série de questões de justiça social e permite ajudar um bom número de pessoas que lhes são gratas por seus cuidados. Porém, dada a forma que elas tomaram até aqui, 
as intervenções políticas e militantes inegavelmente favoreceram, ao mesmo tempo: a criminalização das trabalhadoras do sexo e de outras pessoas que participam, por vontade própria, da economia de rua; a deportação (e, frequentemente, a posterior detenção) de migrantes interpeladas por ocasião das operações contra o tráfico; e o encaminhamento das vítimas oficiais do tráfico humano que conseguiram evitar a detenção a empregos sem futuro e muito mal pagos, donde o risco de que estas pessoas retornem à suas atividades anteriores para ganhar mais (Bernstein, 2007a, 2007b; Brennan, 2010). Em nível internacional, um dos resultados mais deploráveis do programa antitráfico da era Bush foi o término do financiamento de projetos dirigidos por trabalhadoras do sexo que se recusaram a assinar o incontornável 'juramento antiprostituição' da TVPA. Ora, no passado esses grupos haviam jogado um papel decisivo na difusão de informações sobre as maneiras de se proteger das sequelas do tráfico e na mobilização do seu conhecimento íntimo do meio para identificar as vítimas potenciais do tráfico humano (Change, 2008).

Como se pode constatar, o fator religioso em si mesmo não determina a natureza da resposta política diante das desigualdades sexuais e de gênero. Os/as evangélicos/as conservadores/as demonstram a mesma relutância que outros grupos de pressão política quando se trata de se desprender dos imperativos da mundialização neoliberal para inventar um modo de luta eficaz contra o tráfico. A aliança entre conservadores/ as cristãos/ãs e feministas laicas estimulou a administração Bush a se concentrar sobre um número limitado de casos de tráfico, que envolvem trabalhadoras do sexo, e a negligenciar as violações de direitos em outros setores de emprego onde grassa o tráfico humano-violações denunciadas pelas campanhas predominantemente laicas dos anos 1990. Ademais, para além das divergências entre protagonistas quanto a se é necessário centralizar a ação no trabalho do sexo ou no trabalho em seu sentido amplo, observa-se um consenso inédito entre todas as partes laicas e religiosas - quanto ao melhor viés para lutar contra o tráfico: o da justiça penal e o do desenvolvimento do aparelho carcerário.

Outra resposta feminista, muito distante da que propõem os principais grupos laicos ou religiosos, seria a de centrar a atenção 
sobre os fatores estruturais que levam os indivíduos dos dois sexos a optar por condutas de risco em termos de migração ou de empregos superexploradores. Isso suporia evidentemente uma análise crítica das principais características da mundialização neoliberal - correlação entre o montante da dívida externa e as diretrizes para empréstimos, flutuações de preços nos mercados mundiais de matérias primas, políticas de desenvolvimento econômico. Um conjunto de elementos que estimulam os países envididados a recorrer às remessas de fundos por trabalhadores migrantes para responder às crises econômicas e equilibrar suas finanças nacionais.

Portanto, não se poderia afirmar que a influência da religião na política seja necessariamente conservadora e que, inversamente, uma política mais laica seja automaticamente mais progressista. Para as feministas, o desafio na matéria não é tanto optar por uma defesa do religioso ou do profano, mas o de enfrentar a dominação ao mesmo tempo religiosa e laica do protestantismo sobre a política americana. Essa é uma questão crucial e o desenvolvimento da igualdade de gênero dependerá da dinâmica e da eficácia das alianças entre militantes feministas. Para isso, elas deverão atacar as duas facetas da influência protestante, reconhecendo a diversidade das tradições religiosas e ao mesmo tempo as suas diferenças internas, inclusive dentro do protestantismo.

\section{REFERÊNCIAS}

AGUSTíN, Laura María. Sex at the Margins: Migration, Labour Markets, and the Rescue Industry. London \& New York: Zed Books, 2007.

BILL, Baue. Marriott Combats Child Sexual Exploitation. 11 December, 20006. SocialFunds.com. Disponível em: <www.socialfunds.com/news/article.cgi/2179/html >.

BERNSTEIN, Elizabeth. The Sexual Politics of the 'New Abolitionism'. Differences: A Journal of Feminist Culture Studies, vol. 18, $\mathrm{n}^{\circ}$ 3, $2007 \mathrm{a}$.

BERNSTEIN, Elizabeth. Temporarily Yours: Intimacy, Authenticity, and the Commerce of Sex. Chicago, University of Chicago Press: 2007b.

BERNSTEIN, Elizabeth. Militarized Humanitarianism meets Carceral Feminism: The Politics of Sex, Rights, and Freedom in Contemporary AntiTrafficking Campaigns. Signs: Journal of Women in Culture and Society, Special Issue: "Feminists Theorize International Political Economy", vol. 36, n¹, 2010. 
BLUMENFELD, Laura. Anti-Prostitution Effort Targets Pimps and Johns. The Washington Post, 15 Dezembro, 2005. Disponível em: <www.msnbc.msn.com/id/10473309/>.

BOYER, Paul. The Evangelical Resurgence in 1970s American Protestantism. In: SCHULMAN, Bruce J., ZELIZER, Julian E. (Eds.). Rightward Bound: Making America Conservative in the 1970s. Cambridge: Harvard University Press, 2008.

BRENNAN, Denise (2010). Key Issues in the Resettlement of Formerly Trafficked Persons in the United States. University of Pennsylvania Law Review, vol. 158, n 6, 2010. CASTELLI, Elizabeth. Theologizing Human Rights: Christian Activism and the Limits of Religious Freedom. In: FEHER, Michel, KRIKORIAN, Gaëlle, MCKEE, Yates (Eds.). Nongovernmental Politics. New York: Zone Books, 2007.

CHACÓN, Jennifer M. Misery and Utopia: Understanding the Failure of the U.S. Efforts to Stop Human Trafficking. Fordham Law Review, vol. 74, n 6, 2006.

CHANGE / Center for Health and Gender Equity. Policy Brief: Implications of U.S. Policy Restrictions for HIV Programs Aimed at Commercial Sex Workers. Change, Agosto, 2008. Disponível em: <www.nswp.org/>.

DOEZEMA, Jo. Forced to Choose: Beyond the Voluntary vs. Forced Prostitution Dichotomy. In: KEMPADOO, Kemala, DOEZEMA, Jo (Eds.). Global Sex Workers: Rights, Resistance, and Redefinition. New York: Routledge, 1998.

FELDMAN, Stephen M. Law \& Religion: A Critical Anthology. New York, New York University Press, 2000.

GOODSTEIN, Laurie. For a Trusty Voting Bloc, a Faith Shaken. New York Times, 7 Outubro, 2007.

GOTTSCHAL, Marie. The Prison and the Gallows: The Politics of Mass Incarceration in America. New York, Cambridge University Press, 2006.

GREEN, John Clifford. The Faith Factor: How Religion Influences American Elections. Westport: Praeger Publishers, 2007.

HERTZKE, Allen D. Freeing God's Children: The Unlikely Alliance for Global Human Rights. Lanham: Rowman \& Littlefield, 2004.

HUMAN RIGHTS WATCH. The Small Hands of Slavery: Bonded Child Labour in India. New York: Human Rights Watch, 1996.

JAKOBSEN, Janet R., PELLEGRINI, Ann. Obama's Neo-New Deal: Religion, Secularism and Sex in Political Debates Now. Social Research, vol. 76, $n^{\circ}$ 4, 2009.

JEWELL, Dawn Herzog. Red-Light Rescue: The 'Business' of Helping the Sexually Exploited Help Themselves. Christianity Today, Janeiro, 2007.

KIMBALL, Dan. The Emerging Church: Vintage Christianity for New Generations. Grand Rapids: Zondervan, 2003.

KLEIN, Naomi. Fences and Windows: Dispatches from the Front Lines of the Globalization Debate. New York: Picador, 2002.

Mandrágora, v.25, n. 1, 2019, p. 289-306 
KRISTOF, Nicholas. kristof.blogs.nytimes.com, 3 Fevereiro, 2004a.

KRISTOF, Nicholas. When the Right is Right. New York Times, 22 Dezembro, 2004b. Disponível em: <www.nytimes.com>.

MCLAREN, Brian. A Generous Orthodoxy. Grand Rapids: Zondervan, 2004.

MCLAREN, Brian. Personal Interview with Elizabeth Bernstein, 10 Novembro, 2008.

MILLER, John. A Statement From Ambassador John R. Miller. 15 Dezembro, 2006, HumanTrafficking.org. Disponível em: <www.humantrafficking.org/updates/524>.

NEWS BLAZE. Private Groups Spearhead Anti-Trafficking Efforts. New Blaze, 2007. Disponível em: <http://newsblaze.com/story/20070214151716tsop.nb/newsblaze/TOPSTORY/ Top-Stories.html>. Acesso em: 15/4/2007.

ROSS, Andrew (Ed.). No Sweat: Fashion, Free Trade, and the Rights of Garment Workers. New York: Verso, 1997.

SAUNDERS, Penelope. Prohibiting Sex Work Projects, Restricting Women's Rights: The International Impact of the 2003 U.S. Global AIDS Act. Health and Human Rights: An International Journal, vol. 7, $\mathrm{n}^{\circ}$ 2, 2004.

SHAPIRO, Nina. The New Abolitionists. Seattle Weekly, 25 Agosto, 2004.

SODERLUND, Gretchen. Running from the Rescuers: New USA Crusades Against Sex Trafficking and the Rhetoric of Abolition. NWSA Journal, 17 Março, 2005.

STEINFELS, Peper. Bishops Steer Middle Course on Politics. New York Times, 5 Novembro, 1995.

UNITED STATES CONGRESS. Victims of Trafficking and Violence Protection Act of 2000. Washington: 106th Congress, 2000.

UNITED STATES CONGRESS. Trafficking Victims Protection Reauthorisation Act of 2003. Washington: 108th Congress, 2003.

UNITED STATES CONGRESS. Trafficking Victims Protection Reauthorisation Act of 2005. Washington: 109th Congress, 2005.

VITAL VOICES GLOBAL PARTNERSHIP. Conference on PublicPrivate Partnerships to End Human Trafficking and Forced Labour: New Business Solutions to a Global Challenge. Hong Kong: 19 Abril, 2007.

WIJERS, Marjan, LAP-CHEW, Lin. Trafficking in Women: Forced Labour and Slavery-Like Practices in Marriage, Domestic Labour, and Prostitution. Utrecht: Foundation Against Trafficking in Women, 1999. 